\section{Treasure island: pinning down a model ecosystem}

Lounging on Craig Venter's yacht in the South Pacific a couple of years ago, Neil Davies contemplated the tiny island of Moorea. Venter, famous for his work on the human genome, was sailing around the world to catalogue the microscopic life of the oceans. But Davies was pondering a more audacious goal: a plan to sequence an entire island. He mentioned the plan to a scientist on Venter's crew: "He just laughed," Davies remembers.

But Davies was on to something. He and a band of ecologists are launching the Moorea Biocode Project, which aims to turn the island into something like a model organism for tropical ecology. Christopher Meyer, a seasnail expert at the University of Florida, Gainesville, is the plan's coordinator. Meyer says it will build on the ideas and technologies behind the scientific movement known as DNA barcoding, which classifies species according to a specific stretch of their genetic sequence. But Meyer says the Moorea project will go further.

He and his colleagues plan to collect multiple genetic and ecological data about each species on Moorea, which lies $15 \mathrm{~km}$ northwest of Tahiti. They will deposit the information in linked databases. Meyer hopes this will give scientists more information than barcoding a single DNA sequence. "Barcoding is great, and a lot of people are excited about it, but it can only answer questions about one narrow space," Meyer says. "We intend to fill our data set with additional information so that we can answer a broader set of questions."
The Biocode team will meet next month to begin designing databases. Meanwhile, entomologist Rosie Gillespie - based, like Davies, at the University of California, Berkeley - will begin collecting insects on Moorea and sequencing their DNA. Then, in March, French icthyologist Serge Planes of Perpignan University will start sampling fish from Moorea's reefs; he hopes to collect $80 \%$ of the 600 fish species in four-and-a-half weeks. Researchers intend to start using these data immediately to look at topics from invasive species to biodiversity.

Nancy Knowlton, a coral-reef expert not involved with the Biocode project, says such data could resolve many unanswered questions. For instance, she says, it is often hard to identify tropical reef fishes, many of which have been described only in small journals. Having a DNA code linked to a visual key could help biologists to make quicker, more accurate identifications. And that could help them to understand crucial parts of reef ecosystems, such as how many species live on them and how well they are doing.

"Our estimate of the number of species on reefs rests on incredibly shaky ground," says Knowlton, who directs the Center for Marine Biodiversity and Conservation at Scripps Institution of Oceanography in La Jolla, California. ${ }^{\alpha}$ These molecular tools have the potential to help us fine-tune those estimates to get a total sense of diversity, and what we're losing as the reefs degrade."

\section{IMAGE UNAVAILABLE FOR COPYRIGHT REASONS}

Pacific crews: collecting genetic data from all life on Moorea shoulds shed light on biodiversity.

The Biocode scientists also want to learn about the general properties of ecosystems. Moorea is less diverse than other islands farther east, so it may serve as a reference site that can be compared with more complex systems in Australia, Papua New Guinea and southeast Asia. "It's like comparing the processes of Caenorhabditis elegans with humans; that's a very powerful approach," says Davies.

Moorea is a logical choice for a model system of ecology, experts say, because it has been

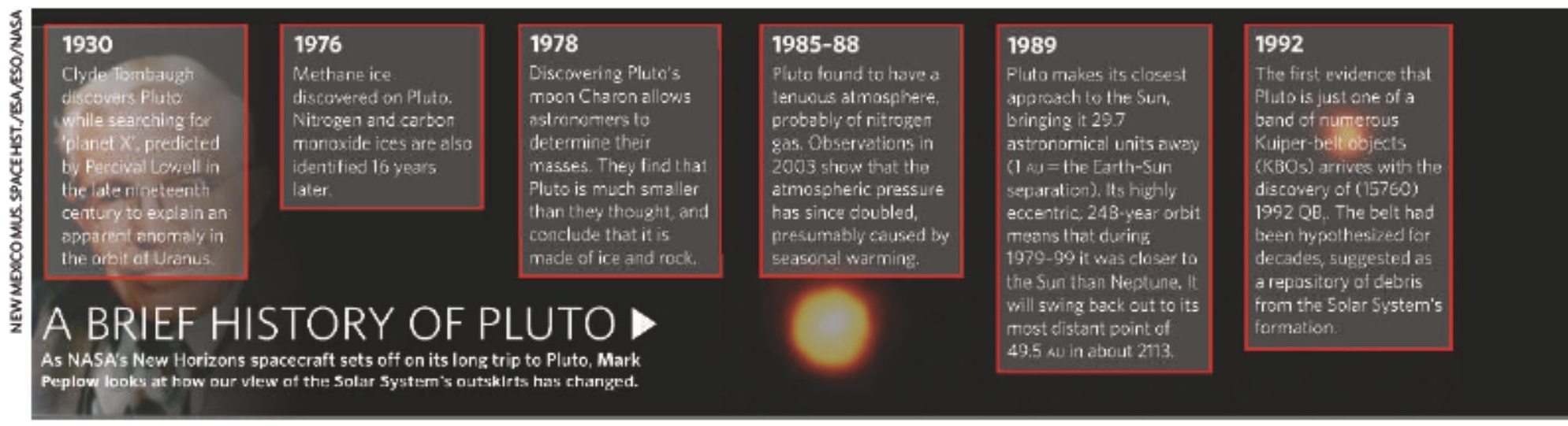


IMAGE

\section{UNAVAILABLE FOR COPYRIGHT REASONS}

well studied by researchers at two field stations there for decades. The project can also tap into other, similar efforts that are already under way, such as the Census of Marine Life, in which Knowlton is involved.

Putting a whole island under the microscope won't be easy. But the Biocode scientists say they are building on a tide of change that is revolutionizing taxonomy and ecology. ${ }^{\alpha}$ We have technological challenges; we have sampling challenges," Meyer admits. "But the idea of barcoding has really hit a tipping point. This is the perfect time to try something like this." Erika Check

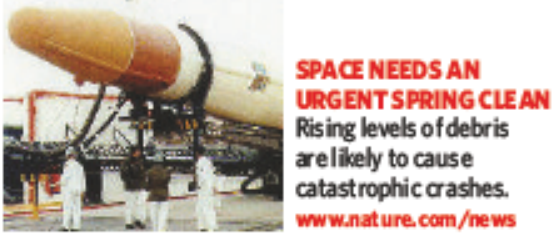

\section{Bad data fail to halt patents}

Two patent applications filed by the California Institute of Technology will proceed despite concerns over the accuracy of data they contain, Nature has learned.

The patents were filed on behalf of the institute's president, David Baltimore, and Luk Van Parijs, formerly a professor at the Massachusetts Ins titute of Technology. Van Parijs was considered a rising star in the field of immunology, but was sacked last year for fabricating data in at least one published paper. Several of his papers use duplicate images, but none of his co-authors has been implicated in any misconduct

Unlike scientific papers, patent applications do not depend ondata buton claims to have conceived a new invention. Inventors often include data, however, to demonstrate the novelty or usefulness of their claims, or to increase the enforceability of the patent once granted.

In the United States, in contrast to many other countries, inventors must sign a declaration affirming that everything in their application is true to the best of their knowledge. The inclusion of false data, even by mistake, could be an infringement of the oath, and thus against the law. Or it could form the basis for questioning the patent later, says Alan Grimaldi, co-chair of the intellectualproperty group at Howrey law firm in Washington DC.

The applications were based on work carried out during Van Parijs's postdoc time in Baltimore's lab; the only other person on them is Lili Yang, a research scientist in the lab. They describe a novel method of gene therapy in which bone-marrow stem cells are infected with a virus to introduce extra genes, then transplanted into a patient where they produce modified immune cells. Depending on the genes inserted, the technique could treat HIV or cancer, the inventors claim.

The research upon which this is based has notbeen questioned. But the patent applications contain at least two instances in which identical images are labelled as coming from different cell populations; three others may also be wrongly identified. When questioned by Nature, Baltimore admittedone of the errors and said he would cor rect it; he is considering the others. He insists, however, that Van Parijs is not responsible. "The patents are fine, and we're proceeding with them," he says.

"Somebody sent in the wrong file. It probably happened in the patent office after we sent them the data."

The status of false data in patents has already come under scrutiny this month. An application on human embryonic stem cells filed by South Korean cloner Woo Suk Hwang of Seoul National University includes data on a cell line discredited by an investigation into his work. His university has said the application will proceed after amendments have been made. If granted, however, some fear it could block patents by other researchers, or that Hwang mightprofit financially from others' work.

The Van Parijs applications may also raise concernsif not corrected. The gene therapy described is a promising area of research, and other work suggests the principle may well be valid. For example, Derek Sant'Angelo at the Memorial Sloan-Kettering Cancer Center in New York has made modified immune cells using a similar approach. In general, the existence of invalid data in patentsintentional or not - would be "a concern" to other inventors, says Sant'Angelo. Eugenie Samuel Reich

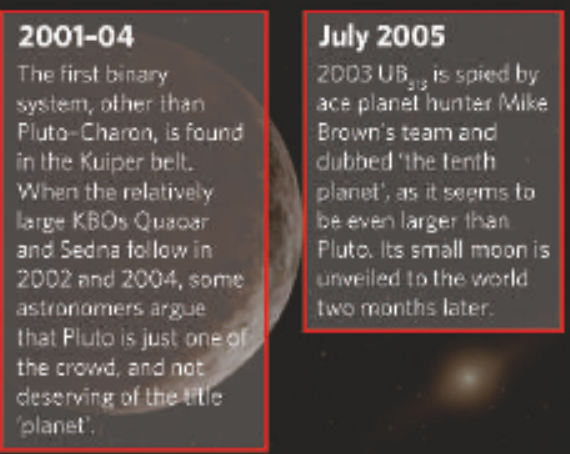

October 2005

Two tiny moons are

lound around fltailo, each between 50 and 160 kilometres arross The find supports the theory that fluto snd its satel ites formed $\mathrm{na}$ massive collision, rathe than a capture event

January 2006
Astronomers in Hawaii
find that Piuto's surface
temperature is $-230^{\circ} \mathrm{C}$.
ten degrees coaler than
Charon. The difference
is blamed on Ihe
jevaporation of nitrogen
cefram Pluto's surface
keeping the planet cool.

19 January 2006 The New Horizons cratt launches, off to probe the Kuiper belt. It will try to discover it Pluto has any seological activity, or even an intemal liquid ocean. Sampling the atmosphere should help explain why it rapidly leaks into space. With the craft goes the man who started it all: a small vial contains Clyde Tnmhangh's athes.

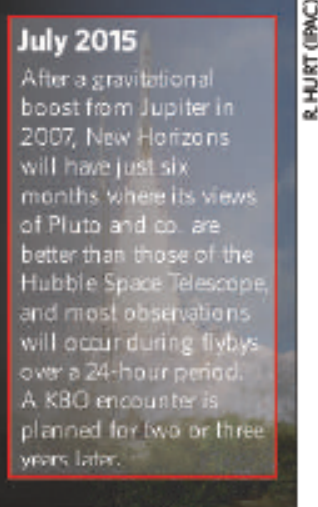

